\title{
EEFEKTIVITAS SOP SIMPATIKA DALAM PELAYANAN VERVAL DAN PERSETUJUAN TUNJANGAN GURU DI KEMENTERIAN AGAMA KABUPATEN LAMONGAN
}

\author{
Faradina Zerin, Nur Faizah, Ubaidillah Zuhri \\ UIN Sunan Ampel, Surabaya - Indonesia |
}

\begin{abstract}
Abstrak: Tujuan dari penelitian ini adalah mengetahui keefektifan SOP SIMPATIKA, verval data, dan publikasi informasi SOP SIMPATIKA. Selain itu penelitian ini juga memberikan gambaran berupa pelayanan SOP SIMPATIKA yang ada di kemenag Kabupaten Lamongan. Penelitian ini menggunakan metode penelitian Kuantitatif. Analisis data berupa angket yang disebar kepada guru yang berkepentingan dalam urusan SIMPATIKA. Kemudian, hasil akhir analisis data yang didapat dari penelitian ini berupa angka yang pada akhirnya digunakan untuk menjadi tolak ukur dari tujuan penelitian awal yaitu tentang keefektivan SOP SIMPATIKA. Subjek dalam penelitian ini adalah guru yang berkepentingan dalam urusan SIMPATIKA dan Admin SIMPATIKA kemenag. Setelah penelitian ini berakhir maka hasil yang didapatkan adalah tentang keefektifan SOP SIMPATIKA, verval data aplikasi SIMPATIKA dan publikasi pelayanan SOP SIMPATIKA.
\end{abstract}

Keywords: efektivitas SOP, verval data dan publikasi, Simpatika

\section{Pemdahuluan}

Efektivitas adalah tingkat keberhasilan dalam mencapai tujuan atau sasaran. Efektivitas ini sesungguhnya merupakan suatu konsep yang lebih luas yang mencakup berbagai faktor di dalam maupun di luar diri seseorang. Dengan demikian, efektivitas tidak hanya dapat dilihat dari sisi produktivitas, tetapi juga dapat dilihat dari sisi persepsi atau sikap individu.1

\footnotetext{
${ }^{1}$ Roymond H. Simamora, Buku Ajar Pendidikan dalam Keperawatan, (Jakarta : 2008, Buku Kedokteran EGC), 31
} 
Selain itu, efektivitas juga dapat dilihat dari bagaimana tingkat kepuasan yang dicapai oleh seseorang. Dengan demikian, efektivitas merupakan suatu konsep yang sangat penting, karena mampu memberikan gambaran mengenai keberhasilan seseorang dalam mencapai sasaran atau tujuan, atau tingkat pencapaian tujuan.2

Efektivitas berasal dari kata "efektif" yang mengandung pengertian dicapainya keberhasilan dalam mencapai tujuan yang telah ditetapkan. Efektivitas selalu terkait dengan hubungan antara hasil yang diharapkan dengan hasil yang sesungguhnya dicapai. Efektivitas mengandung arti "keefektif-an" (effectiveness) pengaruh/efek keberhasilan, atau kemanjuran/kemujaraban. Dengan kata lain efektivitas menunjukkan sampai seberapa jauh pencapaian hasil yang sesuai dengan tujuan yang ditetapkan.3

Indikator efektivitas dalam arti tercapainya sasaran atau tujuan yang telah ditentukan sebelumnya merupakan sebuah pengukuran dimana suatu target telah tercapai sesuai dengan apa yang telah direncanakan. Selain itu, konsep efektivitas merupakan suatu konsep yang bersifat multidimensional, artinya dalam mendefinisikan efektivitas berbeda-beda sesuai dengan dasar ilmu yang dimiliki walaupun tujuan akhir dari efektivitas adalah selalu sama yaitu pencapaian tujuan. 4

Dengan demikian, efektivitas merupakan suatu keadaan yang menunjukkan keberhasilan atau kegagalan dalam mencapaai tujuan yang telah ditetapkan terlebih dahulu. Dari sini dapat terlihat bahwa suatu pekerjaan dapat dikatakan efektif apabila pekerjaan tersebut dapat mewujudkan tujuan yang telah ditentukan. Efektivitas tidak hanya memberikan pengaruh atau kesan, akan tetapi berkaitan juga dengan keberhasilan tujuan, penetapan

\footnotetext{
${ }^{2}$ Roymond H. Simamora, (Jakarta : 2008, Buku Kedokteran EGC), 31

${ }^{3}$ Lysa Angrayani dan Yustiati, Efektivitas Rehabilitasi Pecandu Narkotika Serta Pengaruhnya Terhadap Tingkat Kejahatan Di Indonesia (Ponorogo : Uwais Inspirasi Indonesia, 2018), 13

${ }^{4}$ Lysa Angrayani dan Yustiati, (Ponorogo : Uwais Inspirasi Indonesia, 2018), 14
} 
standar, efektivitas, penepatan sasaran, keberadaan program, materi, berkaitan dengan metode atau cara, sarana atau fasilitas dan juga dapat memberikan pengaruh. Dengan melihat penjelasan diatas, dapatlah disimpulkan bahwa efektivitas lebih melihat kepada hasil akhir atau output sehingga apabila hasil akhirnya tidak sesuai dengan tujuan yang telah ditetapkan dan tidak pula memberikan efek atau pengaruh terhadap sasaran yang dituju, maka tidak bias dikatan efektif.5

Berbicara tentang efektivitas, penelitian ini membahas tentang efektivitas SOP (Standard Operating Procedure). SOP sendiri merupakan acuan atau dapat dikatakan pedoman baku dalam melaksanakan suatu aktivitas tertentu. Suatu unit kerja tertentu dapat dikatakan berhasil dan bekerja secara benar apabila semua aktivitas pekerjaannya mengacu pada SOP pada bidangnya.6 Istilah SOP sering kali digunakan untuk menyebut semua dokumen yang mengatur kegiatan operasional organisasi. Misalnya seperti protokol, prosedur tetap, instruksi kerja, diagram alir, dan lain sebagainya. Dengan bahasa yang berbeda namun memiliki substansi yang sama. Menurut Istyadi Insani mengatakan SOP adalah pedoman pelaksanaan administrasi perkantoran dalam rangka peningkatan pelayanan. Selanjutnya menurut Gareth $\mathrm{R}$. Jones menyatakan bahwa SOP merupakan bagian dari peraturan tertulis yang membantu untuk mengontrol perilaku anggota organisasi.7

SOP sangat dibutuhkan dalam organisasi sebagai pedoman pedoman dalam melakukan suatu proses pekerjaan. Bisa dibayangkan, tanpa pedoman yang baku (SOP) tentunya akan menimbulkan kebingungan. SOP bersifat mengikat seluruh pelaksana pekerjaan yang meliputi seluruh oranf yang bekerja

\footnotetext{
${ }^{5}$ Mukhtar, Hapzi Ali Dkk, Efektivitas Pimpinan (Yogyakarta : Deepublish, 2012), 27-28

${ }^{6}$ Rifka, Step By Step Lancer Membuat SOP (Depok : 2017, Huta Media), 13

${ }^{7}$ Arnina P, Langkah-Langkah Efektif Menyusun SOP (Depok : Huta Publisher, 2016), 31
} 
didalam perusahaan.8 Manfaat dari SOP yaitu dapat memengaruhi bertahan atau tidaknya sebuah perusahaan. SOP dibuat untuk menjalankan pekerjaan agar dapat bekerja dengan efektif dan efisien.9 Sedangkan tujuan utama dari pembuatan SOP dalah memebrikan kemudahan bagi para orang yang berkepentingan dalam membacanya, sehingga orang tersebut dapat mengerti dan dapat menjalankan prosedurnya dengan benar. Oleh sebab itu diperlukan suatu pertimbangan untuk dapat menentukan bentuk SOP yang digunakan, yaitu jumlah keputusan yang akan diambil dan jumlah langkah yang akan dilakukan dalam suatu proses.10

Dalam hal ini SOP dalam penelitian ini membahas tentang SIMPATIKA. SIMPATIKA sendiri merupakan aplikasi milik Direktorat Jenderal Pendidikan Islam (Ditjen Pendis) Kementerian agama (Kemenag) untuk mengelola seluruh kepentingan PTK (Pendidik dan Tenaga Kependidikan) utamanya untuk mengelola tunjangan profesi guru (TPG). Pertama kali dirilis pada tanggal 20 Mei 2013 dengan nama Padamu Negeri milik Kemendikbud, kemudian dikembangkan oleh Kemenag dan pada tanggal 17 Agustus 2015 berganti nama menjadi SIMPATIKA. Aplikasi SIMPATIKA yang merupakan sistem informasi milih instansi pemerintah di Indonesia, telah beberapa kali mengalami update sejak pertama kali diluncurkan. Namun sejak tahun 2013 aplikasi SIMPATIKA belum sekalipun dievaluasi kinerjanya.11

Melalui layanan SIMPATIKA, Kementerian Agama mengembangkan beragam program kerja untuk kepentingan pendidik dan tenaga kependidikan, meliputi: Digitalisasi Portofolio

\footnotetext{
${ }^{8}$ Arnina, (Depok : Huta Publisher, 2016), 32

${ }^{9}$ Rifka, Step By Step Lancer Membuat SOP (Depok : 2017, Huta Media), 13

${ }^{10}$ Adika fuad assidiqi dan nawa prastyo, E-book,

${ }^{11}$ Umdatur Rosyidah, Kusrini, Henderi, Evaluasi Usability Pada Aplikasi

Simpatika Direktorat Jenderal Pendidikan Islam Kementerian Agama, Sensitek 2018, Stmik Pontianak, 12 Juli 2018, diakses pada tanggal 02 oktober 2020

https://books.google.co.id/books?id=ZprnDwAAQBAJ\&pg=PT91\&dq=SO P+adalah\&hl=id\&sa=X\&ved=2ahUKEwj27666u5fsAhVRWysKHT62C88 Q6AEwAnoECAUQAg\# $\mathrm{v}=$ onepage $\& \mathrm{q}=\mathrm{SOP} \% 20$ adalah $\& \mathrm{f}=$ false
} 
Pendidik dan Tenaga Kependidikan, Bantuan/ Beasiswa Pendidik dan Tenaga Kependidikan, Tunjangan Pendidik dan Tenaga Kependidikan, Diklat Pendidik dan Tenaga Kependidikan, Sertifikasi Pendidik, Pemetaan Mutu Pendidik dan Tenaga Kependidikan, Verifikasi dan Validasi (VerVal) Nomor Regristasi Guru (NRG), Verifikasi dan Validasi (VerVal) Inpassing, Nomor Pendidik Kemenag (NPK), Alih Tugas Tambahan, Surat Keterangan Melaksanakan Tugas (SKMT) \& Surat Keterangan Beban Kerja (SKBK) Online, Seleksi Sertifikasi Guru Kemenag, Registrasi Uji Kompetensi Guru (UKG), eTunjangan, Tata Kelola Pengawas, ePKB (tindak lanjut hasil UKG), dan beragama program lainnya. Dengan system ini diharapkan data-data yang masuk dapat lebih akurat dan terus menerus dapat diperbaharui sehingga dapat digunakan sebagai dasar pengambilan keputusan. Penggunaan sumber daya yang efektif, efisien, dan optimal dalam pengambilan keputusan berbasis SIMPATIKA di Seksi Pendidikan Madrasah Kementerian Agama salah satu kuncinya terletak pada ketersediaan data dan informasi yang akurat dan tepat waktu. Hal tersebut merupakan fungsi dari SIMPATIKA.12

Kementerian Agama Kabupaten Lamongan merupakan salah satu fasilitas yang diberikan pemerintah kepada warga kabupaten Lamongan sebagai mediator untuk menyalurkan semua keinginannya terutama dalam bidang Pendidikan, haji, sampai urusan pernikahan. Akan tetapi penelitian kali ini akan lebih berfokus pada pelayanan SOP SIMPATIKA yang berada dalam kasi Pendidikan Madrasah (PENMA). Dalam pelayanan SIMPATIKA tentunya admin yang menjabat sudah berusaha sangat optimal mungkin dalam pelayanan SOP. Akan tetapi untuk memperjelas dan mengukur kepuasan pelanggan dalam pelayanan tersebut maka peneliti hadir dalam menganalisis dan mendeskripsikan tingkat kepuasan pelanggan dalam pelayanan SOP ini.

${ }^{12}$ Fery Tholkhah Aji, Pengambilan Keputusan Penetapan Peserta Sertifikasi Dan Tunjangan Guru Berbasis Sistem Informasi Manajemen Di Seksi Pendidikan Madrasah Kementerian Agama Kabupaten Banyumas, (Thesis : Institut Agama Islam Negeri Purwokerto , 2019), 7-8 
Dengan latar belakang penelitian yang berfokus pada efektivitas SOP SIMPATIKA dalam verval data dan tunjangan guru, maka peneliti akan melakukan penelitian yang berjudul efektivitas SOP SIMPATIKA dalam pelayanan verval dan persetujuan tunjangan guru di Kementerian Agama Kabupaten Lamongan.

Berdasarkan latar belakang diatas, maka rumusan masalah yang kami dapatkan adalah : (a) Bagaimana Efektivitas SOP SIMPATIKA di Kemenag Kabupaten Lamongan ? (b) Bagaimana SOP pelayanan SIMPATIKA di Kemenag Kabupaten Lamongan ? (c) Bagaimana publikasi informasi SOP SIMPATIKA di Kemenag Kabupaten Lamongan?

Tujuan dari penulisan ini adalah : (a) untuk mengukur dan mendeskripsikan efektivitas SOP SIMPATIKA dalam verval dan persetujuan tunjangan guru (b) untuk mengetahui dan mendeskripsikan SOP pelayanan SIMPATIKA (c) untuk mengetahui dan mendeskripsikan publikasi informasi SOP SIMPATIKA.

\section{Metodologi}

Metode penelitian ini menggunakan jenis penelitian kuantitatif. Dalam pelaksanaannya penelitian ini bertempat di Kantor Kementerian Agama Kabupaten Lamongan dengan rentan waktu 05 Oktober - 12 Oktober 2020. Penilitian ini menggunakan sampel yang telah dihitung dari banyaknya populasi admin setiap sekolah di Kabupaten Lamongan yang berkunjung ke Kemenag Lamongan serta responden selaku admin dalam pengoprasionalan aplikasi SIMPATIKA yang ada di Kantor Kementerian Agama Lamongan.

Teknik pengumpulan data dalam penelitian ini berupa pengumpulan data primer yang berarti data yang diperoleh secara langsung dari responden. Angket atau quisioner adalah serangkaian pertanyaan tertulis yang diajukan peneliti kepada para responden untuk mendapatkan jawaban secara tertulis. Sehubungan dengan itu, Suharsimi Arikunto mengemukakan pendapatnya yaitu angket dan quisioner ialah penyelidikan pada suatu masalah yang banyak menyangkut kepentingan umum (orang banyak) dilakukan dengan jalan mengedarkan suatu formulir daftar pertanyaan, diajukan 
secara tertulis kepada sejumlah obyek untuk mendapatkan jawaban atau tanggapan (respon) tertulis seperlunya.13 Dan teknik lain yang digunakan yaitu observasi dan wawancara.

Instrumen yang digunakan dalam penelitian ini yaitu berupa quisioner yang berupa pertanyaan-pertanyaan yang dijawab dengan jawaban pilihan ganda. Dengan Teknik analisis data berupa pengelompokan data, penyajian data setiap variabel dan mendeskripsikannya kemudian diakhiri dengan simpulan dan saran.

\section{Hasil dan Pembahasan}

\section{Efektivitas SOP SIMPATIKA di Kemenag Kabupaten Lamongan}

Standart Operating Prosedure (SOP) merupakan suatu petunjuk untuk mempermudah masyarakat umum dalam melakukan sesuatu agar tidak keliru atau tepat pada tujuan yang diinginkan. Begitu pula dengan gambaran SOP SIMPATIKA yang ada di Kemenag Lamongan. SOP memberikan kemudahan bagi pengguna dalam melakukan aktivitasnya. SOP dibutuhkan untuk mengatur petugas maupun masyarakat dalam melakukan prosedur yang sudah ditetapkan diawal kegiatan. Dalam aplikasi SIMPATIKA sendiri sudah dijelaskan tentang prosedur dan persyaratan yang harus dipenuhi untuk mendapatkan apa yang dituju. SOP dikatakan sebagai pedoman atau acuan untuk melaksanakan tugas pekerjaan sesuai dengan fungsi dan alat penilaian kinerja instansi pemerintah berdasarkan indikator-indikator teknis, administratif dan prosedural sesuai dengan tata kerja, prosedur kerja dan sistem kerja pada unit kerja yang bersangkutan.

SOP SIMPATIKA sendiri dapat diakses oleh masyarakat umum, begitu juga dalam pelayanan SIMPATIKA yang ada di kemanag Lamongan sangat mudah dalam aksesnya. Petugas selalu berjaga dalam ruangan sehingga masyarakat umum dapat menemui petugas dengan mudah dengan jam kerja yang telah ditentukan. Masyarakat juga diberi akses yang lebih mudah lagi karena petugas dapat dihubungi kapanpun melalui WhatsApp.

${ }^{13}$ Asep Saepul Hamdi Dan E. Bahruddin, Metode Penelitian Kuantitatif Aplikasi dalam Pendidikan (Yokyakarta : Deepublish 2014), 30 
Penelitian keefektifan SOP SIMPATIKA dilakukan untuk mengetahui tingkat keefektifan dan tingkat kepuasan pelanggan dalam akses SIMPATIKA. Keefektifan SOP diukur melalui angket yang disebarkan kepada guru atau admin sekolah yang datang ke kantor kemenag dalam ruangan PENDMA (Pendidikan Madrasah) khususnya. Angket disebarkan sebanyak 50 orang sebagai sample yang datang dari berbagai perwakilan madrasah. Tingkat keakuratan data diukur melalui pengisian angket secara langsung dengan orang yang bersangkutan.

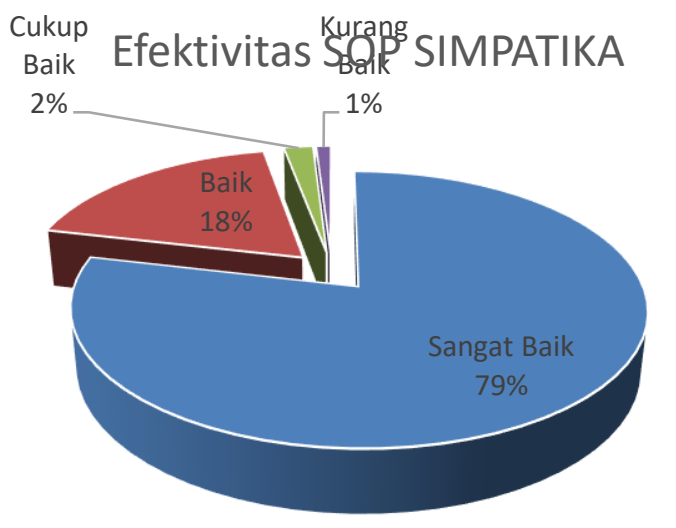

Diagram diatas menunjukkan bahwa tingkat keefektifan SOP SIMPATIKA sangatlah tinggi dengan perhitungan angket yang diperoleh sebelumnya. Tingkat efektifitas dihitung melalui banyaknya soal dalam satu angket yang dikalikan dengan banyaknya keseluruhan angket. Diagram tersebut menunjukkan data sebagai berikut :

\begin{tabular}{|c|l|c|c|}
\hline No & Keterangan & Jumlah & Efektivitas \\
\hline 1 & Sangat Baik & 392 & $79 \%$ \\
\hline 2 & Baik & 93 & $18 \%$ \\
\hline 3 & Cukup Baik & 10 & $2 \%$ \\
\hline 4 & Kurang Baik & 5 & $1 \%$ \\
\hline
\end{tabular}

Jadi dapat disimpulkan bahwa tingkat efektivitas SOP SIMPATIKA dalam pelayanan, kecakapan serta tingkat kepuasan 
pelanggan dikatakan sangat baik karena dibuktikan dengan perhitungan angket yang digambarkan melalui diagram dan diperjelas dengan tabel diatas. Dengan adanya penelitian ini petugas serta Lembaga perkantoran dapat mempertahankan kinerja serta memperbaiki kekurangan. Petugas serta Lembaga dapat mempertahankan tingkat kecakapan serta mudahnya akses bertemu dan dapat memperbaiki fasilitas yang ada.

\section{SOP pelayanan SIMPATIKA di Kemenag Kabupaten Lamongan}

Situs layanan SIMPATIKA ialah sebagai pusat informasi pelayanan PTK Kemenag. Pusat layanan PTK Kemenag merupakan lanjutan dari program Padamu Negeri yang dirintis oleh Kemendikbud sejak 20 Mei 2013 hingga Juni 2015. Mulai 17 Agustus 2015, Kemenag mengembangkan secara mandiri Layanan SIM PTK Online berbasis sistem SIAP Padamu Negeri bekerjasama dengan PT. Telkom Indonesia.

Melalui layanan SIM PTK Online ini, Kemenag mengembangkan beragam program kerja untuk kepentingan PTK Kemenag, meliputi: Digitalisasi Portofolio PTK, Bantuan/Beasiswa PTK, Tunjangan PTK, Diklat PTK, sertifikasi PTK, Pemetaan Mutu PTK, dan beragam program lainnya.

Proses transaksi data pada layanan SIM PTK Online Kemenag akan melibatkan secara berjenjang dari individu PTK, Pimpinan Madrasah/Sekolah, Kantor Kemenag Kab/Kota, Kantor wilayah Kemenag Provinsi, hingga Unit-unit Kerja Kemenag Pusat dengan terpadu.

Keutamaan layanan SIMPATIKA

- Proses cepat secara "Real Time Online"

- Tersedia 24/7 kapan saja dan akses dari mana saja

- Otomasi alur kerja (Automation Workflow) minim interferensi pengguna (user)

- Fleksibel dan modular kastemisasi menyesuaikan dengan dinamisasi regulasi

- Akuntabel sesuai aturan (Rules by System)

- Penerbitan legal dokumen secara elekteronik digital minim kertas (paperless)

- Pengawasan dan pengendalian online terpusat 
Modul dan Fitur yang ada pada Aplikasi SIMPATIKA

- Portal dan Situs Publik

- Aturan dan prosedur

- Pencarian GTK

- Profil singkat GTK

- Statistik rekap keaktifan GTK

- Pencarian kode sertifikasi Mapel

- Login

- Bantuan

SIMPATIKA

- Kelola Kepala Madrasah

- Kelola data siswa

- Kelola rombel/kelas

- Kelola kalender akademik

- Kelola laporan

- Kelola keaktifan guru

- Kelola tenaga kependidikan

- Kelola pengawas

- Kelola kurikulum madrasah

- Kelola jadwal mengajar

- Kelola absen GTK

- Verval kealtifan madrasah (S25)

- SKMT (Surat Keterangan Melaksanakan Tugas)

- SKBK (Surat Keterangan Beban Kerja)

- SKAKPT TPG (Surat Keterangan Analisa Kelayakan Penerima Tunjangan)

- Kelola tunjangan insentif GBPNS

- Kelola PPG (Pendidikan Profesi Guru)

- Verval NRG lanjutan

- Verval ijazah S1/D4

- Linieritas Mapel dengan ijazah S1/D4

- Integrasi dengan Aplikasi SIMPEG verval data PNS

Business Intelegence (BI)

- Dasbos data Guru

- Dasbor data Madrasah

- Rasio Madrasah dan Guru 
- Dasbor rekapitulasi pengelolaan PPG

- Dasrbor rekapitulasi SKAKPT

- Analisa capaian pencairan TPG

- Analisa capaian pencairan tunjangan insentif GBPNS

- Analisa kelebihan, kekurangan, dan distribusi Guru

Dalam pelayanannya, Bapak Mashur selaku Admin SIMPATIKA Kemenag Kab. Lamongan selalu berpatokan pada prosedur-prosedur yang sudah ditulis resmi oleh Kementrian Agama Pusat dalam SOP Pelayanan SIMPATIKA yang dimana prosedur tersebut juga diterapkan pada Kemenag Kab/Kota lainnya.

Seluruh Madrasah juga dapat melihat bagaimana prosedur pelayanan SIMPATIKA di Website Pusat Layanan SIMPATIKA sehingga jika Kepala Madrasah atau Guru hendak menemui Admin SIMPATIKA di Kemenag Kab. Lamongan sudah mengetahui bagaimana prosedur dan apa saja syarat yang harus dibawa atau dilakukan ketika hendak mengurus urusan tersebut. Dan seandainya seorang Kepala Madrasah atau Guru pada saat mengurus urusan tersebut tidak melihat prosedur kemudian tidak memenuhi persyaratannya maka Admin SIMPATIKA Kab. Lamongan akan menunjukan apa saja yang harus di bawa atau dilakukan sebelum mendatangi Admin SIMPATIKA dan jika sudah memenuhi persyaratan barulah Admin SIMPATIKA akan melakukan pelayanan selanjutnya sesuai apa yang tertulis pada prosedur yang ada dalam SOP Pelayanan SIMPATIKA.

Jadi pelayanan SIMPATIKA di Kemenag Kab. Lamongan ini sudah sesuai dengan prosedur yang sudah di tentukan oleh Kementerian Agama Pusat. Hanya saja di karenakan adanya pandemi ini, pelayanan SIMPATIKA dipermudah dengan dapat menghubungi Admin SIMPATIKA melalui WhatsApp.

Oleh karena itu dengan adanya Pandemi Covid-19 ini pihak SIMPATIKA maupun Kemenag sendiri dapat menambahi SOP pelayan khusunya dalam SIMPATIKA yaitu dengan membuat peraturan tentang Pysichal Distancing dengan memenuhi atau mentaati protokol kesehatan sehingga aman baik untuk orang dalam Kantor Kementerian Agama Kab. Lamongan maupun pengunjung luar kantor 


\section{Publikasi Informasi SOP SIMPATIKA di Kemenag Kabupaten Lamongan}

Publikasi Informasi mengenai SIMPATIKA ini sudah dapat dilihat oleh seluruh masyarakat melalui Website Pusat Layanan SIMPATIKA. Di dalam Web tersebut sudah ada SOP dari SIMPATIKA juga, sehingga bagi yang belum mengetahui prosedurprosedur dapat melihatnya melalui Website tersebut.

Juga dengan adanya kemajuan zaman ini, maka semuanya di permudah dengan adanya teknologi yang canggih, dimana PTK (Pendidik dan Tenaga Kependidikan) tidak harus datang ke Kantor Kemenag Kab. Lamongan. PTK dapat menghubungi Admin SIMPATIKA melalui WhatsApp karena segala informasi juga sudah di bagikan melalui WhatsApp yang dirasa pasti semua masyarakat memiliki aplikasi tersebut. PTK dapat mengirim dokumendokumen yang hendak di urus melalui WhatsApp. Sehingga ini sangatlah mempermudah sekali, apalagi di era pandemi saat ini yang memang dianjurkan untuk tidak bertemu banyak orang.

Publikasi informasi SOP SIMPATIKA di Kemenag Kab. Lamongan sendiri, dari data yang kami dapatkan dari pengunjung bahwasannya sangat baik, baik itu dalam pelayanannya sendiri maupun hasil yang ingin didapatkan. Dalam hal ini dapat dikatakan bahwasaanya SOP SIMPATIKA di kantor Kemenag Kab. Lamongan tujuannya tidak hanya mementingkan orang dalam namun juga mementingkan pelayanan dari orang luar. Jadi dapat dikatakan bahwa SOP SIMPATIKA dibuat bukan hanya ditaati oleh admin SIMPATIKA saja tetapi juga untuk ditaati bagi pengguna SIMPATIKA itu sendiri.

\section{Kesimpulan}

Efektivitas SOP SIMPATIKA dalam pelayanan verval dan persetujuan tunjangan guru adalah tingkat keberhasilan dalam mencapai tujuan atau sasaran dalam melaksanakan verval dan persetujuan tunjangan PTK dalam aplikasi SIMPATIKA menggunakan acuan atau dapat dikatakan pedoman baku yang telah ditetapkan oleh pusat. 
Dari hasil penelitian dibuktikan bahwasanya mayoritas pengunjung memilih "Sangat baik" sebanyak 392 orang atau jika dipresentase yaitu 79\%, sehingga dapat dikatakan SOP SIMPATIKA di Kantor Kemenag Kab. Lamongan yaitu sangat baik, baik dalam pelayanannya, sikap, maupun hasil yang diharapkan. Sehingga kelebihan ini harus bisa dipertahankan dan memperbaiki kekurangan yang ada.

Dari hasil wawancara dengan admin SIMPATIKA Kantor Kemenag Kab. Lamongan bapak Mashur S.Ag. M.A. Bahwasannya beliau selalu berpatokan pada prosedur-prosedur yang sudah ditulis resmi oleh Kementerian Agama Pusat dalam SOP Pelayanan SIMPATIKA yang dimana prosedur tersebut juga diterapkan pada Kemenag Kab/Kota lainnya. Bukan hanya adminnya saja tetapi juga Seluruh Madrasah juga dapat melihat bagaimana prosedur pelayanan SIMPATIKA di Website Pusat Layanan SIMPATIKA sehingga jika Kepala Madrasah atau Guru hendak menemui Admin sudah mengetahui bagaimana prosedur dan apa saja syarat yang harus dibawa atau dilakukan ketika hendak mengurus urusan tersebut. Jadi pelayanan SIMPATIKA di Kemenag Kab. Lamongan ini sudah sesuai dengan prosedur yang sudah di tentukan oleh Kementrian Agama Pusat

Hasil dari wawancara admin SIMPATIKA juga bahwasannya publikasi SOP SIMPATIKA di Kantor Kemenag Kab. Lamongan bahwasannya semua Informasi mengenai SIMPATIKA ini sudah dapat dilihat oleh seluruh masyarakat melalui Website Pusat Layanan SIMPATIKA. Di dalam Web tersebut sudah ada SOP dari SIMPATIKA juga, sehingga bagi yang belum mengetahui prosedurprosedur dapat melihatnya melalui Website tersebut.

Publikasi informasi SOP SIMPATIKA di Kemenag Kab. Lamongan sendiri, dari data yang kami dapatkan dari pengunjung bahwasannya sangat baik, baik itu dalam pelayanannya sendiri maupun hasil yang ingin didapatkan. Jadi dapat disimpulkan bahwasannya efektivitas SOP SIMPATIKA dala pelayanan Verval dan persetujuan Tunjangan guru bisa dikatakan sangat baik, tetapi masih ada yang perlu diperbaiki terutama dalam materi pendukung, seperti fasilitas jaringan internet, sarana prasarananya 
dan materi pendukung yang lainnya, sehingga bisa lebih cepat dan nyaman dalam pelayanan SIMPATIKA yang bisa menguntungkan baik warga Kantor Kementerian Agama, maupun pengunjung luar.

\section{References}

Arnina P, 2016. Langkah-Langkah Efektif Menyusun SOP. Depok : Huta Publisher.

Assidiqi Fuad Adika dan Prastyo Nawa, E-book,

Angrayani, Lysa dan Yustiati. 2018. Efektivitas Rehabilitasi Pecandu Narkotika Serta Pengaruhnya Terhadap Tingkat Kejahatan Di Indonesia. Ponorogo : Uwais Inspirasi Indonesia.

Mukhtar, Hapzi Ali Dkk. 2012. Efektivitas Pimpinan. Yogyakarta : Deepublish. 27-28

Rifka. 2017. Step By Step Lancer Membuat SOP. Depok : Huta Media.

Rosyidah, Umdatur. 2018. Kusrini, Henderi, Evaluasi Usability Pada Aplikasi Simpatika Direktorat Jenderal Pendidikan Islam Kementerian Agama, Sensitek 2018, Stmik Pontianak : diakses pada tanggal 02 oktober 2020. https://books.google.co.id/books?id=ZprnDwAAQBAJ\&pg=P T91\&dq=SOP+adalah\&hl=id\&sa=X\&ved=2ahUKEwj27666u5fs AhVRWysKHT62C88Q6AEwAnoECAUQAg\# $\mathrm{v}=$ onepage\&q= SOP\%20adalah\&f=false

Roymond H. Simamora. 2008. Buku Ajar Pendidikan dalam Keperawatan. Jakarta : Buku Kedokteran EGC.

Tholkhah Aji Fery. 2018. Pengambilan Keputusan Penetapan Peserta Sertifikasi Dan Tunjangan Guru Berbasis Sistem Informasi Manajemen Di Seksi Pendidikan Madrasah Kementerian Agama Kabupaten Banyumas, Thesis : Institut Agama Islam Negeri Purwokerto. 